\title{
Risk Factors for Acute Kidney Injury in COVID-19 Patients: A Systematic Review
}

\author{
Dian Daniella ${ }^{1 *}$, Yenny Kandarini ${ }^{2}$, Gede Wira Mahadita ${ }^{2}$ \\ ${ }^{1}$ Department of Internal Medicine, Wangaya General Hospital, Denpasar, Bali, Indonesia; ${ }^{2}$ Department of Internal Medicine, \\ Division of Nephrology and Hypertension, Udayana University Sanglah Hospital, Denpasar, Bali, Indonesia
}

\begin{abstract}
BACKGROUND: Acute kidney injury (AKI) in coronavirus disease-19 (COVID-19) has high incidence and mortality. Risk factors for AKI in COVID-19 patients are not well explored. This systematic review provides a combination of available evidence regarding risk factors of AKI in COVID-19 patients.

METHODS: A systematic research was performed in Medline, Cochrane Central Register of Controlled Trials and ScienceDirect journal databases from 2019 to August 2020. The study selection process was plotted using a Preferred Reporting Items for Systematic Review and Meta-Analyses flow diagram.

RESULTS: Out of 553 studies found, four full-text studies met the inclusion criteria and were included in qualitative analysis. There are 2205 COVID-19 patients with AKI (36.44\%) from 6051 COVID-19 patients. Age was a risk factors for AKI in two studies (odds ratio [OR] 1.03 [p < 0.001], OR 1.03 [p < 0.007]). Critical condition of patient is risk factors for AKI (OR 8.155 [ $=0.006]$ ). Hirsch et al. stated that diabetes mellitus (OR 1.74 [p < 0.001]), cardiovascular disease (OR $1.48[p<0.001])$, and hypertension (OR $1.25[p=0.02])$ are also risk factors. Laboratory results such as elevated procalcitonin (PCT) and estimated glomerular filtration rate (eGFR) $<60 \mathrm{ml} / \mathrm{min} / 1.73 \mathrm{~m}^{2}$ showed positive association to AKI in COVID-19 patients (OR 4.822 [ $p=0.037$ ]; OR 13.451 [ $p=0.016]$ ). A higher sequential organ failure assessment (SOFA) score at admission is one of the risk factors (OR $1.498[p=0.027])$.

CONCLUSION: Demographics, clinical classification of COVID-19, comorbidities, SOFA score, PCT, and eGFR can help clinicians predict AKI in COVID-19 patients.
\end{abstract}

Edited by: Ksenija Bogoeva-Kostovska Citation: Daniella D, Kandarini Y, Mahadita GW. Risk Factors for Acute Kidney Injury in COVID-19 Patients: A Systematic Review. Open Access Maced J Med Sci. 2021 Apr 18; 9(F):118-123. https://doi.org/10.3889/oamjms.2021.5846 Keywords: Acute kidney injury; COVID-19; Risk facto Correspondence: Dian Daniella, Atma Jaya Catholic University, Jakarta, Indonesia. dian.daniella@gmail.com Revised: 25-Mar-202 Accepted: 09-Apr-202 Copyright: $\odot 2021$ Dian Daniella, Yenny Kandarini Gede Wira Mahadita competing interest exist

\section{Introduction}

An outbreak of pneumonia of unknown causes stirred Wuhan, Hubei Province, China, in December 2019. On January 7,2020 , the reason was severe acute respiratory syndrome-coronavirus-2 (SARS-CoV-2), and the disease was called coronavirus disease-19 (COVID-19). Now, COVID-19 is a pandemic that affects the whole world, causing physical health issues, mental health issues, economic issues, and many more. The virus is spreading rapidly, resulting in at least 15 million confirmed cases and more than 640,000 deaths reported as of July 25, 2020 [1]. Clinical symptoms of COVID-19 patients vary, ranging from asymptomatic to respiratory, gastrointestinal to skin manifestations [2].

It was previously believed that lung is the main target of SARS-CoV-2, but other organs can be involved nowadays [3]. Kidney is one of the organ target injuries in COVID-19 due to angiotensin-converting enzyme-2 (ACE-2), the binding site of SARS-CoV-2, which is highly expressed in proximal tubule cells and podocytes [4]. Furthermore, macrophage activation, complement deposition in the renal tubule, and subsequent microvascular injury lead to renal damage in COVID-19 patients [5]. In the systematic review by Kunutsor and Laukkanen, renal complications of COVID-19 are electrolyte disturbances (12.5\%), acute kidney injury $(\mathrm{AKI})(11 \%)$, and $6.8 \%$ for renal replacement therapy [6]. In China, the incidence of $\mathrm{AKI}$ ranges from $0.5 \%$ to $2.9 \%$, whereas in the United States of America (USA), the incidence of AKI ranges from $28 \%$ to $46 \%$ [4]. In France, AKI occurs in $80 \%$ of seriously ill COVID-19 patients [3]. Several current studies suggest that COVID-19 patients with $\mathrm{AKI}$ are associated with a high mortality rate, around 35-41\% [4]. Robbins-Juarez et al. stated that AKI was associated with higher odds of death among COVID-19 patients $(15.27,95 \% \mathrm{Cl} 4.85-48.36)$, with $52 \%$ of mortality rate [7].

High incidence and mortality of COVID-19 patients with $\mathrm{AKI}$ increase our awareness as physicians to this matter. Multiple systematic reviews have assessed the incidence and outcome of it, but to the best of our knowledge, there has not been a systematic review considering the risk factors for AKI in COVID19 patients. Risk factors are essential for clinicians to be better prepared for what lies ahead in managing COVID-19 patients. The present systematic review provides a combination of available evidence regarding 
risk factors of AKI in COVID-19 patients that could provide valuable information to clinicians.

\section{Materials and Methods}

\section{The study sample, design, and setting}

In the present review, we focused on studies that examined the risk factors for AKI in COVID-19 patients who met the following inclusion criteria: (1) Diagnosis of COVID-19 was confirmed with positive real-time reverse transcriptase-polymerase chain reaction (RT-PCR) assay of nasopharyngeal swab or respiratory tract specimens or oral swab, (2) diagnosis of AKI based on 2012 Kidney Disease: Improving Global Outcomes (KDIGO) criteria, (3) AKI occurs in the hospitalization period. Only studies that assess AKI risk factors in COVID-19 patients that measure risk factors effect with odds ratio (OR) were considered. Non-English articles, review articles, and animal studies were excluded from the study. Eligible studies had to be published as full-length articles in peer-reviewed journals.

\section{Search strategy and literature review}

Reviewers searched the Medline, Cochrane Central Register of Controlled Trials (CENTRAL), and ScienceDirect journal databases from 2019 to August 2020. The following keywords used were ("Acute Kidney Injury" OR "AKI") AND ("COVID-19" OR "SARSCOV-2" OR "2019 Novel Coronavirus" OR "2019-nCoV" OR "Coronavirus Disease 2019" OR "coronavirus disease 2019"). Relevant studies, screened based on the title and abstract, were selected after conducting an electronic search. The study selection process was plotted using a Preferred Reporting Items for Systematic Review and Meta-Analyses flow diagram.

\section{Risk of bias}

The risk of bias was independently determined using the Risk of Bias in Non-randomized Studies of Interventions (ROBINS-I) tool by Cochrane. The risk of bias was classified as the low, moderate, severe, and critical risk of bias and no information. Low risk of bias means the study is comparable to a well-performed randomized trial, moderate risk of bias implies the research is sound for a non-randomized review concerning this domain but cannot be considered comparable to a well-performed randomized trial, serious risk of bias means the course has some critical problems in this domain, and critical risk of bias implies the study is too problematic to provide any useful evidence on the effect of the intervention. No information means no information on which to base a judgment about the risk of bias in this domain [8].

\section{Data extraction}

The researchers in the original studies independently collected information regarding the following items: First author's names, year of publication, country, study design, duration of data collection, inclusion criteria, exclusion criteria, number of COVID-19 patients, number of COVID-19 patient with AKI, mean age of COVID-19 patients with AKI, and number of male patients. AKI's risk factors were divided into demographic, comorbidities, laboratory results, clinical criteria, and management.

\section{Results}

Five hundred and fifty-three relevant references were identified in the Medline, CENTRAL, and ScienceDirect based on the studies' title. A manual search of abstracts and citation index from the recognized paper's reference list was done, and three studies were identified. Three studies were duplicates and were removed. The abstracts were also filtered, leading to the removal of 527 reviews that did not identify risk factors of AKI in COVID-19 patients. Eight full-text studies were assessed for eligibility, where three of them were excluded because they did not present risk factors with OR. One study did not state precise statistical analysis. Therefore, it was banned for this study. This filtering process, resulting in four full-text studies, included in qualitative synthesis (Figure 1).

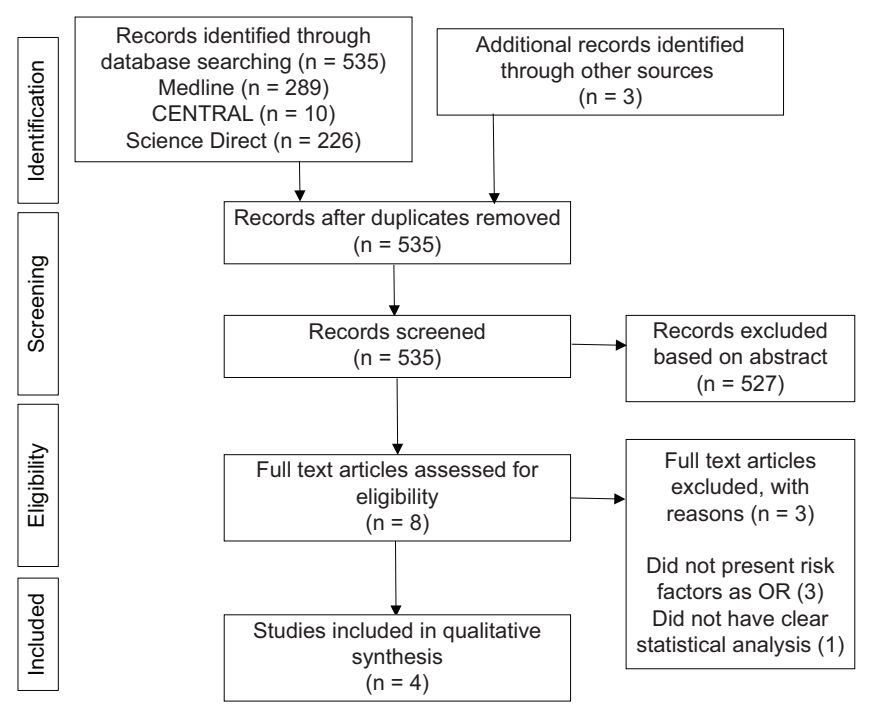

Figure 1: The results of the literature search process used in the current study, using a Preferred Reporting Items for Systematic Reviews and Meta-Analyses flow diagram 


\section{Characteristics of studies}

The risk of bias was determined using the ROBINS-I tool by Cochrane. Overall risk of bias in studies included have moderate risk of bias (Table 1). Moderate risk of bias implies the research is sound for a non-randomized review but cannot be considered comparable to a well-performed randomized trial. All studies were retrospective cohort from two countries: The USA and China (Table 2). Studies have different duration of collecting data, with the longest was by Cui et al. (77 days) [2]. Diagnosis of COVID-19 was defined as a positive RT-PCR assay of nasopharyngeal swab or respiratory tract specimens or oral swab. In all studies, AKI was defined according to the 2012 KDIGO criteria [9]. Two studies only included adult patients, whereas two studies did not state the age limit of included patients. Three studies excluded patients with end-stage kidney disease (ESKD). A total of 6051 COVID-19 patients and 2205 COVID19 patients with AKI (36.44\%) were identified. AKI occurs in $37.3 \%$ of COVID-19 patients in the westernbased study, whereas only $14 \%$ in the eastern-based study. All the patients were the elderly, with the oldest was found in a study by Nimkar et al. (75 [63-85] years) [10], and the youngest was found in a study by Cui et al. (61.05 [48.15-73.92] years) [2]. The patients were predominantly male, with the highest percentage is $83.3 \%$ of the patient in the study by Wang et al. [11].

Table 1: Summary of risk of bias of included studies

\begin{tabular}{|c|c|c|c|c|}
\hline Risk of bias & $\begin{array}{l}\text { Cui } \\
\text { et al. [2] }\end{array}$ & $\begin{array}{l}\text { Hirsch } \\
\text { et al. [12] }\end{array}$ & $\begin{array}{l}\text { Nimkar } \\
\text { et al. [10] }\end{array}$ & $\begin{array}{l}\text { Wang } \\
\text { et al. [11] }\end{array}$ \\
\hline Bias due to confounding & Low risk & Low risk & Low risk & Low risk \\
\hline $\begin{array}{l}\text { Bias in the selection of } \\
\text { participants into the study }\end{array}$ & Low risk & Low risk & Low risk & Low risk \\
\hline $\begin{array}{l}\text { Bias in the classification of } \\
\text { interventions }\end{array}$ & Low risk & Low risk & Low risk & Low risk \\
\hline $\begin{array}{l}\text { Bias due to deviations from } \\
\text { intended interventions }\end{array}$ & Low risk & Low risk & Low risk & Low risk \\
\hline Bias due to missing data & Low risk & Low risk & Low risk & Low risk \\
\hline $\begin{array}{l}\text { Bias in measurement of } \\
\text { outcomes }\end{array}$ & $\begin{array}{l}\text { Moderate } \\
\text { risk }\end{array}$ & Moderate risk & Moderate risk & Moderate risk \\
\hline $\begin{array}{l}\text { Bias in the selection of the } \\
\text { reported result }\end{array}$ & Low risk & Low risk & Low risk & Low risk \\
\hline Overall & $\begin{array}{l}\text { Moderate } \\
\text { risk }\end{array}$ & Moderate risk & Moderate risk & Moderate risk \\
\hline
\end{tabular}

\section{Risk factors for AKI in COVID-19 patients}

Risk factors for AKI in COVID-19 patients are divided into demographic, clinical criteria of COVID-19, comorbidities, laboratory results, clinical score, and management (Table 3). All studies used multivariate logistic regression to evaluate risk factors and measure risk factors effect with $\mathrm{OR}$.

The effect of gender was examined in three studies and was not a significant risk factor for AKI in COVID-19 patients [10], [11], [12]. AfricanAmerican race is also one of the risk factors in two studies [10], [12]. Two other studies did not analyze the African-American race, probably due to the population's limitation as the studies were done in China [2], [11]. Age was a risk factors for AKI in two studies (OR 1.03 [p < 0.001], OR 1.03 [p < 0.007]) [10], [12]. By Wang et al., COVID-19 patients are classified based on their clinical criteria, whereas critical patients are defined as patients with respiratory failure requiring mechanical ventilation or shock or organ failure requiring admission to the intensive care unit. Critical condition of patient is risk factors for AKI (OR 8.155 [p = 0.006]) [11].

Comorbidities are analyzed in three studies, and one study stated that comorbidities are not a risk factor [11]. Hirsch et al. stated that diabetes mellitus (DM) (OR 1.74 [p < 0.001]), cardiovascular disease (OR 1.48 [ $p<0.001]$ ), and hypertension (OR 1.25 [p = 0.02]) are risk factors [12], but Nimkar et al. stated otherwise [10]. Cardiovascular disease is defined as coronary artery disease, heart failure, and peripheral vascular disease by Hirsch et al. [12] and as chronic heart conditions including coronary artery disease, previous myocardial infarction, cardiac arrhythmias, congestive heart failure, presence of pacemaker or defibrillator device, and prior coronary artery bypass grafting or percutaneous coronary intervention by Nimkar et al. [10].

Laboratory results such as elevated procalcitonin (PCT) and estimated glomerular filtration rate (eGFR) $<60 \mathrm{ml} / \mathrm{min} / 1.73 \mathrm{~m}^{2}$ showed positive association to AKI in COVID-19 patients (OR 4.822 $[p=0.037] ;$ OR $13.451[p=0.016])$ [11]. Sequential organ

Table 2: Characteristic of studies

\begin{tabular}{|c|c|c|c|c|c|c|c|c|c|c|c|}
\hline \multirow[t]{2}{*}{ Author } & \multirow[t]{2}{*}{ Country } & \multirow[t]{2}{*}{ Study design } & \multirow[t]{2}{*}{$\begin{array}{l}\text { Duration of } \\
\text { data collection } \\
\text { (days) }\end{array}$} & \multirow[t]{2}{*}{$\begin{array}{l}\text { Inclusion } \\
\text { criteria }\end{array}$} & \multirow[t]{2}{*}{ Exclusion criteria } & \multirow[t]{2}{*}{$\begin{array}{l}\text { COVID-19 } \\
\text { patients }\end{array}$} & \multicolumn{2}{|c|}{$\begin{array}{l}\text { COVID-19 } \\
\text { patients with } \\
\text { AKI } \\
\end{array}$} & \multirow[t]{2}{*}{$\begin{array}{l}\text { Mean age patient } \\
\text { COVID-19 patient } \\
\text { with AKI (years) }\end{array}$} & \multicolumn{2}{|l|}{ Male } \\
\hline & & & & & & & $\mathrm{n}$ & $\%$ & & $\mathrm{n}$ & $\%$ \\
\hline $\begin{array}{l}\text { Cui } \\
\text { et al. [2] }\end{array}$ & China & $\begin{array}{l}\text { Retrospective } \\
\text { cohort }\end{array}$ & 77 & $\begin{array}{l}>18 \text { years old } \\
\text { with COVID-19 }\end{array}$ & $\begin{array}{l}\text { Without laboratory confirmation of } \\
\text { COVID-19 }\end{array}$ & 116 & 21 & 18.10 & $61.05(48.15-73.92)$ & 12 & 57.1 \\
\hline $\begin{array}{l}\text { Hirsch } \\
\text { et al. [12] }\end{array}$ & USA & $\begin{array}{l}\text { Retrospective } \\
\text { cohort }\end{array}$ & 36 & $\begin{array}{l}>18 \text { years old } \\
\text { with COVID-19 }\end{array}$ & $\begin{array}{l}\text { Hospital transfers out of health systems, } \\
\text { multiple admissions for } 1 \text { patient, kidney } \\
\text { transplant, ESKD, serum creatinine not } \\
\text { available or only } 1 \text { serum creatinine } \\
\text { available }\end{array}$ & 5449 & 1993 & 36.58 & $69.0(58.0-78.0)$ & 1270 & 63.7 \\
\hline $\begin{array}{l}\text { Nimkar } \\
\text { et al. [10] }\end{array}$ & USA & $\begin{array}{l}\text { Retrospective } \\
\text { cohort }\end{array}$ & 64 & $\begin{array}{l}\text { Patients with } \\
\text { COVID-19 }\end{array}$ & $\begin{array}{l}1 \text { creatinine value recorded during } \\
\text { hospital stay, ESKD on chronic dialysis, } \\
\text { did not yet have a definite outcome of } \\
\text { mortality or discharge }\end{array}$ & 370 & 179 & 48.38 & 75 (63-85) & 101 & 56.4 \\
\hline $\begin{array}{l}\text { Wang } \\
\text { et al. [11] }\end{array}$ & China & $\begin{array}{l}\text { Retrospective } \\
\text { cohort }\end{array}$ & 9 & $\begin{array}{l}\text { Patients with } \\
\text { COVID-19 }\end{array}$ & $\begin{array}{l}\text { History of maintenance dialysis, ESKD, } \\
\text { renal transplantation, tuberculous } \\
\text { pericardial effusion, medical record } \\
\text { missed }\end{array}$ & 116 & 12 & 10.34 & $66.0(56.8-73.0)$ & 10 & 83.3 \\
\hline
\end{tabular}


Table 3: Risk factors for AKI in COVID-19 patients

\begin{tabular}{|c|c|c|c|c|c|c|c|c|}
\hline \multirow[t]{2}{*}{ Risk factors } & \multicolumn{2}{|l|}{ Cui et al. [2] } & \multicolumn{2}{|l|}{ Hirsch et al. [12] } & \multicolumn{2}{|l|}{ Nimkar et al. [10] } & \multicolumn{2}{|l|}{ Wang et al. [11] } \\
\hline & OR $(95 \% \mathrm{Cl})$ & $p$ value & OR $(95 \% \mathrm{Cl})$ & $p$ value & OR $(95 \% \mathrm{Cl})$ & $p$ value & OR $(95 \% \mathrm{Cl})$ & $p$ value \\
\hline Male & ** & & not & & not & & not & \\
\hline African-American race & ** & & $1.23(1.01-1.50)$ & 0.04 & $2.01(1.1-3.6)$ & 0.02 & ** & \\
\hline Age & ** & & $1.03(1.03-1.04)$ & $<0.001$ & $1.03(1.01-1.05)$ & 0.007 & not & \\
\hline Clinical classification (critical) & ** & & ** & & ** & & $8.155(1.848-35.983)$ & 0.006 \\
\hline \multicolumn{9}{|l|}{ Comorbidities } \\
\hline CKD & ** & & ** & & $3.3(1.4-7.9)$ & 0.008 & ** & \\
\hline DM & ** & & $1.76(1.49-2.07)$ & $<0.001$ & not & & ** & \\
\hline Cardiovascular disease & ** & & $1.48(1.22-1.80)$ & $<0.001$ & not & & ** & \\
\hline Hypertension & ** & & $1.25(1.04-1.5)$ & 0.02 & not & & ** & \\
\hline Hyperlipidemia & ** & & ** & & $1.8(1.03-3.01)$ & 0.03 & ** & \\
\hline \multicolumn{9}{|l|}{ Laboratory results } \\
\hline PCT elevated & ** & & ** & & ** & & $4.822(1.095-21.228)$ & 0.037 \\
\hline eGFR $<60 \mathrm{ml} / \mathrm{min} / 1.73 \mathrm{~m}^{2}$ & ** & & ** & & ** & & $13.451(1.617-111.891)$ & 0.016 \\
\hline Higher SOFA score at admission & $1.498(1.047-2.143)$ & 0.027 & ** & & ** & & ** & \\
\hline \multicolumn{9}{|l|}{ Management } \\
\hline Mechanical ventilation & ** & & $10.7(6.81-16.7)$ & $<0.001$ & ** & & ** & \\
\hline Vasoactive medication usage & ** & & $4.53(2.88-7.13)$ & $<0.001$ & ** & & ** & \\
\hline
\end{tabular}

failure assessment (SOFA) score consists of multiple parameters, such as $\mathrm{PaO}_{2}$ and $\mathrm{FiO}_{2}$, on mechanical ventilation including continuous positive airway pressure, platelets number, Glasgow Coma Scale, bilirubin value, mean arterial pressure of administration of vasoactive agents required, and creatinine value or urine output. A higher SOFA score at admission is one of the risk factors (OR $1.498[p=0.027])$ [2].

Associated with SOFA score and clinical classification of COVID-19 mentioned before, one study analyzed specifically mechanical ventilation and vasoactive medication usage. This study reported positive association with risk of AKI with ORs 10.7 $(p<0.001)$ and $4.53(p<0.001)$, respectively [12].

\section{Discussion}

This study is the first systematic review for risk factors of AKI in COVID-19 patients to the best of our knowledge. Around 500 titles were reviewed to identify four studies with sufficient quality to identify risk factors of AKI. This systematic review included more than 9000 COVID-19 patients from the USA and China. A broad range of risk factors, including demographics, clinical criteria of COVID-19, comorbidities, laboratory results, clinical score, and management, was extracted for eligible articles.

Schiffl stated that female, especially premenopausal women, has lower susceptibility to hospital-acquired AKI than men [13]. This could be explained by the harmful effect of testosterone and the protective effect of estrogen in mice. Kang et al. stated that estrogen depletion in female mice significantly increased the renal inflammatory cytokines' expression levels and was attenuated by estrogen supplementation [14]. Contrary to these findings, gender was not a significant risk factor for AKI in COVID-19 [10], [11], [12]. This finding occurs because most of the patients are the elderly, whereas most female patients are menopausal. Therefore there is no protective effect from estrogen.
From eligible studies in this systematic review, AKI occurs in $37.3 \%$ COVID-19 patients in the westernbased study, whereas only $14 \%$ in the eastern-based study. The western population has higher expression of ACE-2 in kidneys, which may contribute to a higher rate of AKI in Western countries [10]. AfricanAmerican race is also one of the risk factors in two studies [10], [12]. This may be related to socioeconomic status disparities [15]. African-American population have higher rate of undiagnosed hypertension and diabetes, which predispose them to higher risk of AKI [16]. Global improvement in access to quality health care may lower rates of $A K I$ and attenuate racial inequality [15]. African-American population also tend to have a more severe clinical course and worse outcomes of COVID-19, which contributes to a higher incidence of AKI [8]. The presence of sickle cell gene in most African-American population predisposes them to higher incidence of AKI [16]. People with sickle cell disease may develop vascular defects that lead to hypoxia within renal medulla, resulting in concentrating defect in renal medulla. A concentrating defect hinders renal function to maintain stable body hemodynamic response to volume depleted state, thus predispose body to AKI [17].

Age was a risk factors for AKI in two studies (OR 1.03 [p < 0.001], OR 1.03 [p < 0.007]) [10], [12]. Older age has consistently been reported as a risk factor for worse outcomes, including mortality and AKI in COVID19 patients. This is due to multiple reasons such as higher rise of cytokine in the elderly with COVID-19 which leads to cytokine storm [10]. Multiple studies have stated the role of cytokine storm in COVID-19. Virusinduced cytokine storm might exert indirect effects on renal tissue [11]. Cytokine storm could cause intrarenal inflammation, increased vascular permeability, volume depletion, and cardiomyopathy, which leads to the cardiorenal syndrome [10]. The elderly are more prone to AKI due to kidney senility, comorbidities, and medical procedure in general [18]. Kidney function declines after the biologic ages of 30-40 years and changes such as parenchymal calcifications and focal narrowing of renal arteries are reported [19]. Comorbidities may also play a role, as patients tend to have more comorbidities as 
they got older. The elderly is often subjected to medical procedures, such as contrast and nephrotoxic drugs, which can induce AKI [18]. Contrary to the previous studies, Wang et al. did not put age as a significant risk factor for AKI [11]. Wang et al. haves a significantly lower number of patients $(n=116)$ compared to the previous two studies $(n=5449$ and $n=370$ ) that did not meet the requirements of event per variable, so the results may not be robust [11].

Critical condition (OR 8.155 [ $p=0.006]$ ) [12], higher SOFA score at admission (OR 1.498 [p 0.027]) [2], and usage of mechanical ventilation (ORs 10.7 [ $p$ 0.001]) and vasoactive medication (4.53 [p < 0.001]) [12] are positively associated with AKI in COVID-19 patients. All of this represent more severe COVID-19. More severe COVID-19 will lead to more severe hypoxemia. Hypoxemia will cause an increase in adenosine triphosphate hydrolysis that exceeds synthesis resulting in intrarenal vasoconstriction decreased renal perfusion, and drop of GFR resulting in AKI. eGFR $<60 \mathrm{ml} / \mathrm{min} / 1.73 \mathrm{~m}^{2}$ is associated with AKI (OR 13.451 [ $p=0.016]$ ) [11]. Mechanical ventilation may further raise the risk of $\mathrm{AKI}$ due to acute tubular necrosis secondary to abdominal compartment syndrome from high peak airway pressure and intraabdominal hypertension [10].

Hirsch etal. stated that DM (OR 1.74 [p<0.001]), cardiovascular disease (OR 1.48 [p $<0.001])$, and hypertension (OR 1.25 [ $p=0.02]$ ) are risk factors [12]. Microvascular injuries in DM lead to microinfarcts and decreased amount of nephrons, hence renal functional reserve reduction. Diabetic hyperglycemia induces secondary metabolic pathway formations such as non-enzymatic glycation and pathways of polyols. The metabolites of non-enzymatic glycation cause disturbances in the production of extracellular matrix components leading to glomerular occlusion. The pathway of polyols presents sorbitol as a metabolite, which in large quantities leads to hyperosmotic stress and consequent cellular damage [18].

Cardiovascular disease is risk factors for AKI in COVID-19 patients. Cardiovascular disease stated by Hirsch et al. consists of coronary artery disease, heart failure, and peripheral vascular disease [12]. This can be explained due to cardiorenal syndrome [20]. Emerging reports have demonstrated a high prevalence of hypertension among COVID-19 patient [21]. Hypertension is one of the risk factors for developing AKI in COVID-19 patients [12]. Hypertension will cause stress to the vessel walls, resulting in reduced elasticity of the tunica intima and stenosis of the lumen, thereby contributing to a decrease in renal blood flow and, consequently, increases the susceptibility to pre-renal AKI. Hypertension also damages the self-regulatory mechanisms of the renin-angiotensin-aldosterone system, thereby complicating the vasodilatation and vasoconstriction response to ischemic insults and facilitating the occurrence of a pre-renal AKI [18].
Nimkar states that chronic kidney disease (CKD) (OR 3.3 [p = 0.008]) and hyperlipidemia (OR 1.8 [ $=0.03]$ ) are risk factors for AKI [10]. AKI and CKD are closely linked and likely to promote one another [22], [23]. Underlying CKD decreased GFR and increased proteinuria, which strongly associated with AKI [23]. In CKD, there is reduction of viable nephrons that lead to reduction in renal functional reserve. When affected by acute stressors, kidney with CKD cannot maintain functionality for too long, thereby leading to AKI. In terms of ESKD, hyperlipidemia is found to be one of risk factors for it, but the mechanims behind it are not completely understood [18]. Hyperlipidemia is risk factors for ESKD, but the mechanism behind increasing AKI with hyperlipidemia are not completely understood [10].

$\mathrm{PCT}$, more than $0.1 \mathrm{ng} / \mathrm{mL}$, was found to be associated with COVID-19-related AKI [11]. PCT is released by bacterial infectious tissues under the irritation of pro-inflammatory cytokines. High PCT showed secondary bacterial infection in COVID-19 patients and was associated with more severe COVID19. Severe COVID-19 is associated with more severe inflammatory reactions, resulting in a higher risk of kidney damage [24].

Other renal pathogenic factors are the prothrombotic state of COVID-19 [12]. AKI and the prothrombotic state may be linked to each other, as $\mathrm{AKI}$ is associated with active inflammation that causes a hypercoagulable state [25]. COVID-19 will cause hypercoagulability and microangiopathy, resulting in tubular epithelial and podocyte damage, resulting in AKI. Direct virus infection may also cause rhabdomyolysis resulting in kidney damage [26].

Our study has several limitations. First, COVID-19 is a relatively new disease and is still not fully understood, hence, the limited number of studies and poorly understood pathogenesis. Second, included studies were observational studies because this systematic review was designed to identify risk factors of AKI in COVID-19 patients. Therefore, the conclusion of this study may be influenced by the bias of observational studies. Nevertheless, all the included studies have a moderate risk of bias as assessed using ROBINS-I tool by Cochrane.

\section{Conclusion}

It is crucial to know the risk factor for it with high morbidity and mortality of AKI in COVID-19 patients. Some risk factors can be obtained on admissions, such as demographics, clinical classification of COVID-19, comorbidities, and SOFA scores. With further evaluation, such as PCT and eGFR, clinicians can predict AKI in COVID-19 patients. Further researches are still needed to assess risk factors for AKI in COVID-19 patients. 


\section{References}

1. Taher A, Alalwan AA, Naser N, Alsegai O, Alaradi A. Acute kidney injury in COVID-19 pneumonia: A single-center experience in Bahrain. Cureus. 2020;12(8):e9693. https://doi.org/10.7759/ cureus. $9693 \mathrm{x}$

PMid:32802627

2. Cui $X, Y u X$, Wu $X$, Huang $L$, Tian $Y$, Huang $X$, et al. Acute kidney injury in patients with the coronavirus disease 2019: A multicenter study. Kidney Blood Press Res. 2020;45(4):612-22. https://doi.org/10.1159/000509517

PMid:32712607

3. Alfano G, Ferrari A, Fontana F, Mori G, Magistroni R, Marianna M, et al. Incidence, risk factors and mortality outcome in patients with acute kidney injury COVID-19: A single-center observational study. Nephrology. 2020;2020:20138230.

4. Fisher M, Neugarten J, Bellin E, Yunes M, Stahl L, Johns TS, et al. AKI in hospitalized patients with and without COVID-19: A comparison study. J Am Soc Nephrol. 2020;31(9):2145-57. https://doi.org/10.1681/asn.2020040509

PMid:32669322

5. Fominskiy EV, Scandroglio AM, Monti G, Calabrò MG, Landoni G, Dell'Acqua $A$, et al. Prevalence, characteristics, risk factors, and outcomes of invasively ventilated COVID-19 patients with acute kidney injury and renal replacement therapy. Blood Purif. 2021;50(1):102-9. https://doi.org/10.1159/000508657 PMid:32659757

6. Kunutsor SK, Laukkanen JA. Renal complications in COVID19: A systematic review and meta-analysis. Ann Med. 2020;52(7):345-53.

\section{PMid:32643418}

7. Robbins-Juarez SY, Qian L, King KL, Stevens JS, Husain SA, Radhakrishnan J, et al. Outcomes for patients with COVID-19 and acute kidney injury: A systematic review and meta-analysis. Kidney Int Rep. 2020;5(8):1149-60. https://doi.org/10.1016/j. ekir.2020.06.013

PMid:32775814

8. Sterne JA, Hernán MA, Reeves BC, Savović J, Berkman ND, Viswanathan $\mathrm{M}$, et al. ROBINS-I: A tool for assessing risk of bias in non-randomised studies of interventions. BMJ. 2016;355:i4919.

PMid:27733354

9. International Society of Nephrology. KDIGO clinical practice guideline for acute kidney injury. Kidney Int Suppl. 2012;2:1-138.

10. Nimkar A, Naaraayan A, Hasan A, Pant S, Durdevic M, Suarez $\mathrm{CN}$, et al. Incidence and risk factors for acute kidney injury and its effect on mortality in patients hospitalized from Covid-19. Mayo Clin Proc Innov Qual Outcomes. 2020;4(6):68795. https://doi.org/10.1016/j.mayocpiqo.2020.07.003 PMid:32838205

11. Wang J, Wang Z, Zhu Y, Li H, Yuan X, Wang X, et al. Identify the risk factors of COVID-19-related acute kidney injury: A singlecenter. Retrospective cohort study. Front Med. 2020;7:436. https://doi.org/10.3389/fmed.2020.00436

PMid:32850917

12. Hirsch JS, Ng JH, Ross DW, Sharma P, Shah HH, Barnett RL, et al. Acute kidney injury in patients hospitalized with COVID-19. Kidney Int. 2020;98(1):209-18.

PMid:32416116

13. Schiffl H. Gender differences in the susceptibility of hospitalacquired acute kidney injury: More questions than answers.
Int Urol Nephrol. 2020;52(10):1911-4. https://doi.org/10.1007/ s11255-020-02526-7

PMid:32661623

14. Kang KP, Lee JE, Lee AS, Jung YJ, Kim D, Lee S, et al. Effect of gender differences on the regulation of renal ischemiareperfusion-induced inflammation in mice. Mol Med Rep. 2014;9(6):2061-8. https://doi.org/10.3892/mmr.2014.2089 PMid:24682292

15. Grams ME, Matsushita K, Sang $Y$, Estrella MM, Foster MC, Tin A, et al. Explaining the racial difference in AKI incidence. J Am Soc Nephrol. 2014;25(8):1834-41. https://doi.org/10.1681/ asn. 2013080867 PMid:24722442

16. Grigorian A, Gabriel V, Nguyen NT, Smith BR, Schubl S, Borazjani $\mathrm{B}$, et al. Black race and body mass index are risk factors for rhabdomyolysis and acute kidney injury in trauma. $J$ Invest Surg. 2020;33(3):283-90. https://doi.org/10.1080/089419 39.2018.1493162

PMid:30212225

17. Hu J, Nelson DA, Deuster PA, Marks ES, O'Connor FG, Kurina LM. Sickle cell trait and renal disease among African American U.S. Army soldiers. Br J Haematol. 2019;185(3):53240. https://doi.org/10.1111/bjh. 15820

PMid:30859563

18. Yokota LG, Sampaio B, Rocha EP, Balbi A, Prado IS, Ponce D. Acute kidney injury in elderly patients: Narrative review on incidence, risk factors, and mortality. Int J Nephrol Renov Dis. 2018; $11: 217-24$.

PMid:30147352

19. Chao CT, Tsai HB, Lin YF, Ko WJ. Acute kidney injury in the elderly: Only the tip of the iceberg. J Clin Gerontol Geriatr. 2014;5(1):7-12.

20. McCullough PA. Cardiorenal syndromes: Pathophysiology to prevention. Int J Nephrol. 2011;2011:762590.

PMid:21151537

21. Shibata S, Arima H, Asayama K, Hoshide S, Ichihara A, Ishimitsu $\mathrm{T}$, et al. Hypertension and related diseases in the era of COVID-19: A report from the Japanese society of hypertension task force on COVID-19. Hypertens Res. 2020;43(10):1028-46. https://doi.org/10.1038/s41440-020-0515-0

22. Belayev LY, Palevsky PM. The link between acute kidney injury and chronic kidney disease: Curr Opin Nephrol Hypertens. 2014;23(2):149-54. https://doi.org/10.1097/01. mnh.0000441051.36783.f3

PMId:24384553

23. Hsu RK, Hsu C. The role of acute kidney injury in chronic kidney disease. Semin Nephrol. 2016;36(4):283-92. PMid:27475659

24. An PJ, Zhu YZ, Yang LP. Biochemical indicators of coronavirus disease 2019 exacerbation and the clinical implications. Pharmacol Res. 2020;159:104946. PMid:32450346

25. Huang MJ, Wei RB, Su TY, Wang Y, Li QP, Yang X, et al. Impact of acute kidney injury on coagulation in adult minimal change nephropathy. Medicine (Baltimore). 2016;95(46):e5366. https:// doi.org/10.1097/md.0000000000005366 PMid:27861367

26. Batlle D, Soler MJ, Sparks MA, Hiremath S, South AM, Welling PA, et al. Acute kidney injury in COVID-19: Emerging evidence of a distinct pathophysiology. J Am Soc Nephrol. 2020;31(7):1380-3. https://doi.org/10.1681/asn.2020040419 PMid:32366514 